\title{
Bioremediation of Waste Water from an Industrial Effluent System in Nigeria Using Pseudomonas aeruginosa: Effectiveness Tested on Albino Rats
}

\author{
Akehinmi Michael Olawale* \\ Biochemical Engineering Laboratory, Department of Chemical Engineering, Obafemi, Awolowo University, Ile-Ife 220005, Osun State, Nigeria
}

\begin{abstract}
The bioremediation potential of Pseudomonas aeruginosa in removing some heavy metals from industrial effluent waste water in Lagos state, Nigeria was investigated. The effectiveness of this bioremediation was tested on albino rats. The common heavy metals known to be pollutants in oil-laden wastewater tested for in the wastewater are Cadmium (Cd), Chromium (Cr), Nickel (Ni), lead (Pb), Selenium (Se), Arsenic (Ar) and Zinc ( $\mathrm{Zn})$. These metals are poisonous to the body system when used. Having determined the concentrations of these metals in the effluent waste water by Atomic Absorption Spectrophotometric test, the results revealed that that $\mathrm{Pb}$, Se, As and $\mathrm{Cd}$ are present at concentrations 0.2843 parts per million (ppm), $19.418 \mathrm{ppm}, 5.02 \mathrm{ppm}$ and $0.104 \mathrm{ppm}$ respectively. These values fall out of the range required by World health Organization (WHO) standard. Nickel and $\mathrm{Cr}$ are present at concentrations of 0.070 and $0.050 \mathrm{ppm}$ and were found to be within the range of WHO standard. Zinc was not detected at all.

The raw water was first treated with live catfishes and Albino rats respectively to determine the effect of the contaminants on both aquatic and terrestrial animals. It was observed that the two catfishes died 33hrs and $36 \mathrm{hrs}$ respectively after introduction into the raw water, while the two albino rats died 10 days after introduction into the water. Having detected these effects, the cultured microorganism, Pseudomonas aeruginosa with some nutrients were introduced into the wastewater for bioremediation process. This was compared to another set of experiment involving only the introduction of nutrients without the cultured microorganisms.

At the end of the fifteen (15) experimental days, the resulting bioremediated water having the cultured microorganisms shows that the concentrations of Lead (Pb), Selenium (Se), Arsenic (As), and Cadmium (Cd) had reduced to $0.0100 \mathrm{ppm}, 0.0110 \mathrm{ppm}, 0.0100 \mathrm{ppm}$, and $0.0100 \mathrm{ppm}$ respectively. This implies percentage degradation of $96.43 \%, 99.94 \%, 99.80 \%$ and $90.38 \%$ respectively compared to the one with nutrients only having percentage degradation of $79.49 \%, 90.12 \%, 86.83 \%$ and $67.26 \%$ respectively. The resulting bioremediated water using Pseudomonas aeruginosa was then treated with a live albino rat for forty days in order to verify the removal or reduction of the toxic substance it contained before the experiment. Surprisingly, the rat did fine in good health condition. This concludes the bioremediation potential of Pseudomonas aeruginosa.
\end{abstract}

Keywords: Bioremediation; Waste water; Heavy metals; Albino rats; Pseudomonas aeruginosa

\section{Introduction}

One of the necessities of life that plants, animals and humans cannot but do without is water. This is needed in a purer form as plants, animals and humans cannot survive if it is loaded with toxic chemicals or harmful microorganisms [1]. Polluted water with prolonged exposure has several effects on human health, as it may lead to cancers, birth defects and various sicknesses.

Wide scale production, transport use and disposal of petroleum globally have made it a major contamination in both prevalence and quantity in the environment. The oil gets mixed with the river or marine water by many ways such as accidental spills or discharge of refineries and oil terminals in river or other water bodies [2]. The petrochemical industries and refineries are quite useful for developing a nation and adding more quality to life. However, various wastes are being generated through these sectors. The unwholesome and environmentally unacceptable pollution effects of these wastes have been reported world-wide [3-5].

Waste water released by the refineries, petrochemical industries and oil storage facilities are characterized by the presence of large quantities of crude oil products, polycyclic and aromatic hydrocarbons, phenols, metal derivatives, surface-active substances, sulfides, naphthylenic acids and other chemicals [6]. Treatment of this wastewater is quite problematic and their purification is ineffective especially with the use of chemical and mechanical methods. Therefore the need calls for a better method. Bioremediation according to [6] is a new method of oil spill clean-up that is far more effective than any of the above methods, and involves the use of microorganisms (Petrophiles) to breakdown complex materials into simple end products. The use of microbes to detoxify and clean up contaminated water has brought about a safe environment today. Nigeria known to be one of the oil producing countries is faced with the challenges of oil spillage problems and our

*Corresponding author: Akehinmi Michael Olawale, Biochemical Engineering Laboratory, Department of Chemical Engineering, Obafemi, Awolowo University, Ile-Ife 220005, Osun State, Nigeria, Tel: 234-703-594-1063; E-mail: mjay4ever@yahoo.com

Received January 20, 2014; Accepted February 25, 2014; Published March 05, 2014

Citation: Olawale AM (2014) Bioremediation of Waste Water from an Industrial Effluent System in Nigeria Using Pseudomonas aeruginosa: Effectiveness Tested on Albino Rats. J Pet Environ Biotechnol 5: 166. doi:10.4172/21577463.1000167

Copyright: () 2014 Olawale AM. This is an open-access article distributed under the terms of the Creative Commons Attribution License, which permits unrestricted use, distribution, and reproduction in any medium, provided the original author and source are credited. 
Citation: Olawale AM (2014) Bioremediation of Waste Water from an Industrial Effluent System in Nigeria Using Pseudomonas aeruginosa: Effectiveness Tested on Albino Rats. J Pet Environ Biotechnol 5: 166. doi:10.4172/2157-7463.1000167

\begin{tabular}{|c|c|}
\hline Chemical & Concentration (g/l) \\
\hline $\mathrm{KH}_{2} \mathrm{PO}_{4}$ & 4.70 \\
\hline $\mathrm{Na}_{2} \mathrm{HPO}_{4}$ & 3.10 \\
\hline $\mathrm{MgSO}_{4} \cdot 7 \mathrm{H}_{2} \mathrm{O}$ & 0.50 \\
\hline $\mathrm{CaCl}_{2} \cdot 2 \mathrm{H}_{2} \mathrm{O}$ & 0.10 \\
\hline $\mathrm{FeSO}_{4} \cdot 7 \mathrm{H}_{2} \mathrm{O}$ & 0.10 \\
\hline $\mathrm{NaHNO}_{3}$ (Urea) & 0.50 \\
\hline
\end{tabular}

(Sterilized in autoclave at $121^{\circ} \mathrm{C}$ for $15 \mathrm{~min}$, at $15 \mathrm{psia}$ )

Table 1: Composition of minimal salt agar.

\begin{tabular}{|c|c|c|}
\hline Element & Concentration $\mathbf{( p p m )}$ & $\begin{array}{c}\text { Required concentration } \\
\text { WHO Standard } \mathbf{( p p m )}\end{array}$ \\
\hline Chromium $(\mathrm{Cr})$ & 0.050 & 0.050 \\
\hline Lead $(\mathrm{Pb})$ & 0.280 & 0.010 \\
\hline Nickel $(\mathrm{Ni})$ & 0.070 & 0.070 \\
\hline Selenium $(\mathrm{Se})$ & 19.419 & 0.010 \\
\hline Arsenic $(\mathrm{As})$ & 5.020 & 0.010 \\
\hline Cadmium $(\mathrm{Cd})$ & 0.101 & 0.003 \\
\hline
\end{tabular}

Table 2: Result obtained from the AAS test carried out on the effluent water at the start of the experiment.

\begin{tabular}{|c|c|c|c|c|}
\hline \multirow{2}{*}{ Days } & \multicolumn{4}{|c|}{ Concentrations in ppm } \\
\cline { 2 - 5 } & lead $(\mathrm{Pb})$ & Selenium $($ Se) & Arsenic $(\mathrm{As})$ & Cadmium $(\mathrm{Cd})$ \\
\hline 1 & 0.280 & 19.419 & 5.020 & 0.101 \\
\hline 3 & 0.280 & 19.006 & 4.988 & 0.101 \\
\hline 5 & 0.248 & 9.333 & 4.745 & 0.101 \\
\hline 7 & 0.109 & 4.896 & 4.106 & 0.098 \\
\hline 9 & 0.092 & 1.615 & 3.891 & 0.094 \\
\hline 11 & 0.072 & 0.779 & 3.496 & 0.068 \\
\hline 13 & 0.062 & 0.406 & 1.122 & 0.052 \\
\hline 15 & 0.058 & 0.164 & 0.661 & 0.033 \\
\hline
\end{tabular}

These values are measured in duplicates

Table 3: Concentration profile for heavy metals in sample A

water getting polluted with them. This has led to this study, looking at the bioremediation potential of pseudomonas aeruginosa in removing some heavy metals from industrial effluent waste water in Lagos state, Nigeria. The effectiveness of this bioremediation was tested on albino rats, as they have the same physiology related to humans.

\section{Materials and Methods}

\section{Collection of waste water samples and cultured microorganisms}

The water sample was collected from a Nigerian Oil storage facility in a sterilized five liter glass bottle. The microorganism used, pseudomonas aeruginosa, (NCIB 950) was obtained from the Microbiology Department, Obafemi Awolowo University, Ile Ife, Osun State, Nigeria.

\section{Growth medium}

A minimal salt medium consisting of major nutrients for growth and development of the microorganisms was prepared by weighing the salts in Table 1 in $150 \mathrm{ml}$ of distilled water.

\section{Sub culturing of isolate}

Nutrient agar powder $(7 \mathrm{~g})$ was added to $250 \mathrm{ml}$ of distilled water in a $500 \mathrm{ml}$ Erlenmeyer flask. The flask with its content was sterilized inside the autoclave at $121^{\circ} \mathrm{C}$ for $15 \mathrm{~min}$ after which the medium was allowed to cool and dispensed into petri-dishes previously sterilized. Distinct colonies that grew on the Minimal Salt Medium (MSM) were then streaked into the surface of the nutrient agar plates. The plates were then incubated at $30^{\circ} \mathrm{C}$ for $24 \mathrm{~h}$. pure colonies from the nutrient agar were then stored on the nutrient agar slant.

\section{Inoculum preparation}

Thirteen grams of nutrient broth was dissolved in $1000 \mathrm{ml}$ of water in a conical flask and sterilized in the autoclave at $121^{\circ} \mathrm{C}$ for $15 \mathrm{~min}$. After cooling to room temperature, $80 \mathrm{ml}$ of the nutrient broth media and $20 \mathrm{ml}$ of minimal salt agar were measured into a $250 \mathrm{ml}$ conical flask. This was then inoculated with pure culture which has been incubated for $24 \mathrm{~h}$ at $30^{\circ} \mathrm{C}$ (a day old culture). The inoculum was then put inside the incubator shaker set at $30^{\circ} \mathrm{C}$ for $48 \mathrm{~h}$ for proper growth of the organism. One millilitre of the suspension of the organism was used for the biodegradation.

\section{Experimental set-up}

The experimental setup was coded A, B and C. These were done in duplicates. The water sample was dispensed in $250 \mathrm{ml}$ Erlenmeyer flasks. The ones labelled A contained the waste water and the prepared nutrient while the ones coded $\mathrm{B}$ contained waste water, the prepared nutrient and the cultured microorganism, Pseudomonas aeruginosa. Flask $\mathrm{C}$ was the control. Flasks $\mathrm{B}$ were used to measure the effectiveness and the rate of degradability of the introduced cultured microorganism. This was compared with the degradability rate flasks A.

\section{Waste Water Analysis}

\section{Atomic Absorption Spectrophotometric (AAS) test on the waste and treated water}

Atomic Absorption Spectrophotometric test was carried out on the waste and treated water in order to know the concentrations of Cadmium, Chromium, Nickel, lead, Selenium, Arsenic and Zinc present.

\section{Biological test of the wastewater}

Two living catfishes and two white rats (also known as Albino rats) were used for this analysis. The two catfishes were placed in the water sample and the albino rats fed with the water before bioremediation to observe the effects of the pollutants in the water sample on them, so as to predict the condition of the aquatic in the river where the water was taken from.

\section{Results}

The effluent water was initially tested with two (2) live catfishes. The catfishes were introduced into the water, one of the catfishes died within 33 hours of introduction into the water while the second died 2 hours later. The water was also tested with two (2) albino rats, to further confirm the presence and the effect of the contaminants. The two rats were fed with the water and after ten (10) days, one died. The other died three (3) hours later. This is as a result of some poisonous element contained in the water sample.

The water was also tested for some known toxic metals such as Cadmium (Cd), Chromium (Cr), Nickel $(\mathrm{Ni})$, lead $(\mathrm{Pb})$, Selenium (Se), Arsenic (Ar) and Zinc ( $\mathrm{Zn})$ using the Atomic Absorption Spectrophotometer (AAS). The result of the test in Table 2 shows that Lead $(\mathrm{Pb})$, Selenium (Se), Arsenic (As), Cadmium $(\mathrm{Cd})$ is present at concentrations 0.280 parts per million (ppm), $19.419 \mathrm{ppm}, 5.020 \mathrm{ppm}$ and $0.101 \mathrm{ppm}$ respectively. These values fall out of the range required by World health Organization (WHO) standard. Nickel and Cr are present at concentrations of 0.070 and $0.050 \mathrm{ppm}$ and were found to be within the range of WHO standard. Zinc was not detected at all. 
Citation: Olawale AM (2014) Bioremediation of Waste Water from an Industrial Effluent System in Nigeria Using Pseudomonas aeruginosa: Effectiveness Tested on Albino Rats. J Pet Environ Biotechnol 5: 166. doi:10.4172/2157-7463.1000167

\begin{tabular}{|c|c|c|c|c|}
\hline \multirow{2}{*}{ Days } & \multicolumn{4}{|c|}{ Concentrations in ppm } \\
\cline { 2 - 5 } & lead $\mathbf{( P b})$ & Selenium (Se) & Arsenic (As) & Cadmium (Cd) \\
\hline 1 & 0.280 & 19.419 & 5.020 & 0.101 \\
\hline 3 & 0.201 & 15.461 & 5.020 & 0.100 \\
\hline 5 & 0.154 & 10.903 & 4.985 & 0.066 \\
\hline 7 & 0.117 & 4.904 & 3.559 & 0.042 \\
\hline 9 & 0.098 & 1.016 & 2.882 & 0.023 \\
\hline 11 & 0.058 & 0.640 & 0.931 & 0.012 \\
\hline 13 & 0.021 & 0.209 & 0.086 & 0.010 \\
\hline 15 & 0.010 & 0.011 & 0.010 & 0.010 \\
\hline
\end{tabular}

These values are measured in duplicates

Table 4: Concentration profile for heavy metals in sample B.

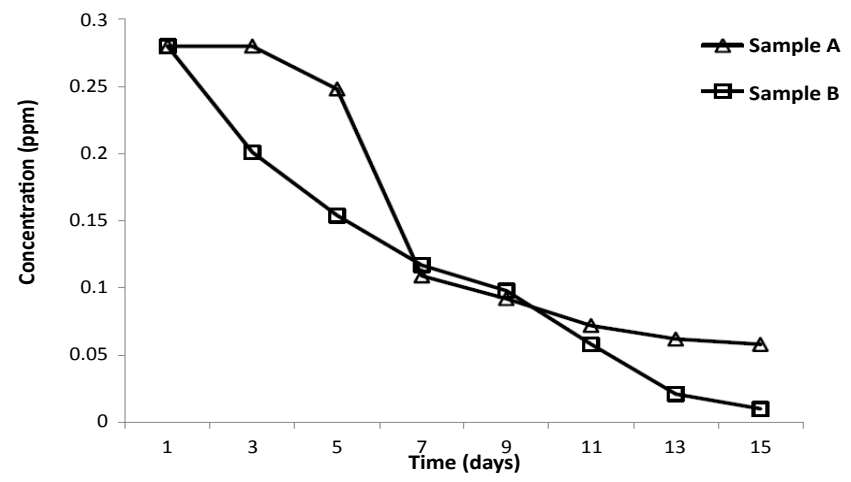

Figure 1: Concentration (ppm) vs Time (days) plot for lead $(\mathrm{Pb})$ in samples $A$ and $B$.

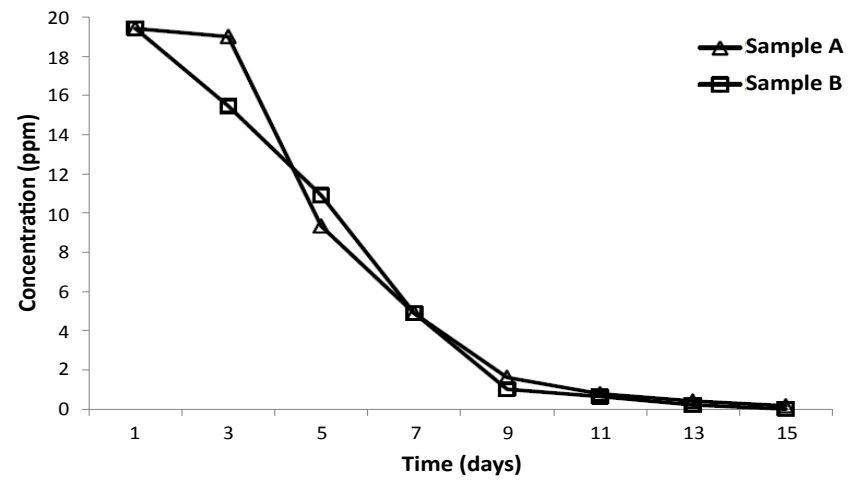

Figure 2: Concentration (ppm) vs Time (days) plot for Selenium (Se) in samples $A$ and $B$.

Tables 3 and 4 revealed the results at the end of the fifteen (15) experimental days. The resulting bioremediated water having the cultured microorganisms coded $\mathrm{B}$ shows that the concentrations of Lead $(\mathrm{Pb})$, Selenium (Se), Arsenic (As), and Cadmium (Cd) had reduced to $0.010 \mathrm{ppm}, 0.011 \mathrm{ppm}, 0.010 \mathrm{ppm}$, and $0.010 \mathrm{ppm}$ respectively. The set of the experiment having the nutrients alone; coded A had the concentrations of Lead (Pb), Selenium (Se), Arsenic (As), and Cadmium $(\mathrm{Cd})$ reduced to $0.058 \mathrm{ppm}, 0.164 \mathrm{ppm}, 0.661 \mathrm{ppm}$ and $0.033 \mathrm{ppm}$ respectively. This implies percentage degradation of $96.43 \%, 99.94 \%, 99.80 \%$ and $90.38 \%$ respectively compared to the one with nutrients only having percentage degradation of $79.49 \%, 90.12 \%$, $86.83 \%$ and $67.26 \%$ respectively. The resulting bioremediated water using Pseudomonas aeruginosa was then treated with a live albino rat for forty days in order to verify the removal or reduction of the toxic substance it contained before the experiment. Surprisingly, the rat did fine in good health condition. This concludes the bioremediation potential of Pseudomonas aeruginosa.

\section{Results and Discussion}

The experimental results presented in Tables 3 and 4 show a trend of decrease in concentration of contaminants in the water sample with time. From the results, it is evident that there is no considerable decrease in the concentration of Lead $(\mathrm{Pb})$ and Cadmium $(\mathrm{Cd})$ in sample A after the first day. The rate of decrease was more pronounced on the fifth day. Regarding sample $\mathrm{B}$, the concentration decrease of Lead $(\mathrm{Pb})$ and Cadmium (Cd) became obvious after the first day. The decrease in concentration of Selenium (Se) for both samples A and B was recorded after the first day while for Arsenic (As), the decrease was obvious for samples $\mathrm{A}$ and $\mathrm{B}$, on the third and fourth day respectively.

Furthermore, the trend observed in Figures 1-4 (concentration of the heavy metals in the samples against time) depicted that the rate of decrease in concentration was higher in sample B than in sample A in terms of the heavy metals considered. This in line with sample B tested on albino rats for forty days and still found in good health. This confirmed the bioremediation potential of Pseudomonas aeruginosa with nutrients' support.

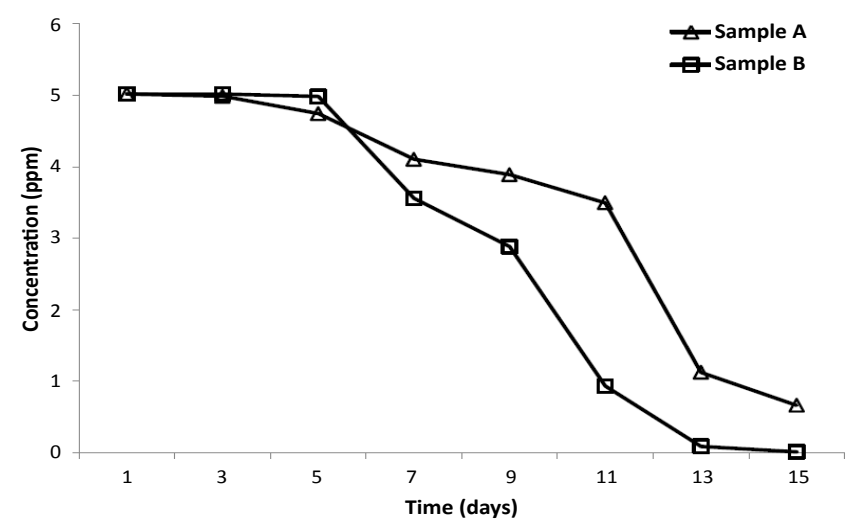

Figure 3: Concentration (ppm) vs Time (days) plot for Arsenic (As) in samples $A$ and $B$.

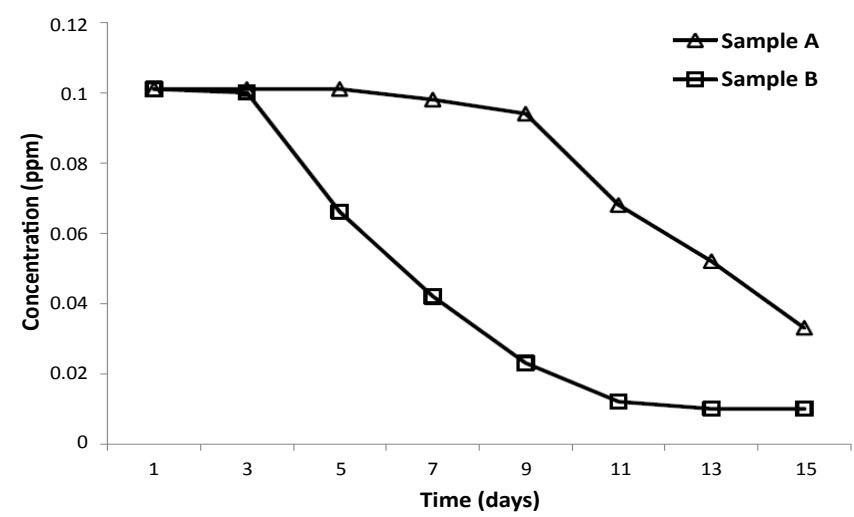

Figure 4: Concentration (ppm) vs Time (days) plot for Cadmium (Cd) in samples $A$ and $B$. 
Citation: Olawale AM (2014) Bioremediation of Waste Water from an Industrial Effluent System in Nigeria Using Pseudomonas aeruginosa: Effectiveness Tested on Albino Rats. J Pet Environ Biotechnol 5: 166. doi:10.4172/2157-7463.1000167

Page 4 of 4

\section{Conclusion}

Bioremediation serves as a very effective method of removing poisonous contaminants and heavy metals from effluent water. It also serves as a cheap and easy means of water treatment which leaves behind non-toxic by product since it involves living organisms with the ability to transform toxic matters in their normal biological activities to yield non-toxic by products.

Based on the experimental results of this study, rate of degradation of effluent water containing heavy metals is best done by introduction of microorganisms like Pseudomonas aeruginosa and some nutrients

\section{Acknowledgement}

The authors wish to acknowledge the technical support rendered by $\mathrm{Mr}$ Obasanjo and Mr. Owolabi in the Department of Microbiology, Obafemi Awolowo University, Ile Ife, Nigeria.

\section{References}

1. Frick CM, Germida JJ, Farrell RE (1999) Assessment of Phytoremediation as an In-Situ Technique for Cleaning Oil-Contaminated Sites. Proceedings of the Phytoremediation Technical Seminar, Calgary Environment Canada 31 May-1 June, 105-124.

2. Singh A, Vinay Kumar, Srivastava JN (2013) Assessment of Bioremediation of Oil and Phenol Contents in Refinery Waste Water via Bacterial Consortium. J Pet Environ Biotechnol 4:145.

3. Kolmert A, Johnson DB (2001) Remediation of acidic waste waters using immobilised, acidophilic sulfate-reducing bacteria. J Chem Technol Biot 76 : 836-843.

4. Vidali M (2001) Bioremediation. An overview. Pure Appl Chem 73: 1163-1172.

5. Guieysse B, Wikström P, Forsman M, Mattiasson B (2001) Biomonitoring of continuous microbial community adaptation towards more efficient phenoldegradation in a fed-batch bioreactor. Appl Microbiol Biot 56: 780-787.

6. Bako SP, Chukwunonso D, Adamu Ak (2008) Bio-Remediation of Refinery Effluents by Strains of Pseudomonas Aerugenosa and Penicillium Janthinellum. Applied Ecology and Environmental Research 6: 49-60. 